\title{
DIGITAL HERITAGE. INHERITANCE OF THE ACCOUNTING ENTRY ON THE INTERNET. DEVELOPMENT PERSPECTIVES IN THE USA AND THE RUSSIAN FEDERATION
}

\section{A. Samoylova ${ }^{1}$, D. Fyodorova ${ }^{2}$}

DOI: http://doi.org/10.15350/L_2/2/1

\section{Abstract}

In this article the entity and a concept of inheritance of the accounting entry of the Internet on the example of social networks reveals, comparing the legislation of the Russian Federation and a row of staffs of the USA. The main gaps of law-enforcement practice are analyzed and conclusions about a possibility of enhancement of rules of law are drawn.

Keywords: Internet, social networks, inheritance of the accounting entry, privacy policy, the virtual property, intellectual property, copyright.

В настоящее время редко встретишь молодого человека, который не имел бы аккаунта в какой-либо социальной сети, особенно при существующем их разнообразии. Исключение составляют жители Северной Кореи, Китайской Народной Республики ввиду принятой ими государственной политики в этой области, а также дальние уголки Земли, где отсутствует Интернет. Появление «Глобальной сети» и возможностей, связанных с её появлением, стало новым явлением прошлого века, а отношения, возникшие благодаря Интернету, начали регулироваться только спустя несколько лет после его появления. Однако следует обратить внимание на то, что и в настоящее время существуют некоторые пробелы в законодательстве развитых стран, в том числе и России.

Рядовой пользователь возможно даже не подозревает о том, сколько сфер и отношений гражданского права он затрагивает в то время, когда пользуется любой социальной сетью. К правам, которые реализуются при использовании, например, того же Facebook, стоит отнести авторское право, передачу и обработку персональных данных, тайну переписки, заключение договора купли-продажи на сайтах и многое другое.

В Соединенных штатах Америки пользователи обратили внимание на то, что после смерти у людей остаются невостребованные акка-

\footnotetext{
${ }_{1}^{1}$ Anastasia Samoylova, student, Saratov state legal academy, Russia.

2Daria Fyodorova, student, Saratov state legal academy, Russia.
}

Research supervisor: Vladimir Gavrilov, Candidate of Law Sciences, Associate Professor, Saratov state legal academy, Russia. 
унты в Интернете (не только в социальных сетях, но и в различных играх, приложениях, на сайтах, форумах). Помимо того, что такие учетные записи сохраняют персональные данные, демонстрируют их, и никто не имеет право удалить их (родственники - потому что у них нет доступа к странице, а сайт- ресурс, где расположена учетная запись - потому, что пользователь не нарушает пользовательское соглашение), они также могут быть подвержены взлому, могут нести материальную ценность (например, остаток виртуальной валюты на кошельке игры, управление коммерческим контрактом) и т.п. Зачастую аккаунты составляют материальную ценность, которая может выразиться в управлении, администрировании конкретной страницей, группой, мероприятием через Интернет, а со смертью держателя страницы возникают убытки в виде невозможности скорого беспроблемного восстановления прежнего положения. Также она выражается в хранении на странице умершего результатов интеллектуальной деятельности (стихи, музыка, видео и другое). Наличие материальной ценности является основополагающим аргументом и ответом на вопрос «почему же стоит включать такие объекты в наследственную массу».

В июне 2005 года в штате Коннектикут был принят закон о предоставлении родственникам доступа к учетной записи пользователя после его смерти. Для получения доступа или копии информации уполномоченному лицу необходимо предоставить письменное заявление и документы, подтверждающие право заявителя [1]. Позже в разных штатах стали появляться похожие нормативные акты, имеющие свои нюансы доступа к объектам цифровой собственности умершего. Например, в Айдахо и Оклахоме родственники умершего могут получить доступ к разным объектам: блогам, почте и социальным страницам, а в Индиане, согласно закону, можно получить доступ к документам и информации, хранящейся в электронном виде, или их копию [2].

1 января 2015 года в штате Делавэр вступил в силу «Закон о фидуциарном доступе к цифровым активам и цифровым счетам» [3] (далее - Закон), в котором указывается, что в случае смерти или признания гражданина недееспособным учетные записи электронной почты, социальных сетей, файлы, учетные записи по учету медицинского страхования, финансового управления, регистрации домена, служб доменных имен веб-хостинга, службы налоговой отчетности, интернет-магазина, партнерские программы и другие онлайн-счета могут быть переданы на основании правоустанавливающих документов третьим лицам опекунам, наследникам, доверителям [4].

Данный Закон закрепил возможность наследования ранее непоименованных объектов гражданского права, и, как показывают отношения, складывающиеся на практике, в некоторых ситуациях это действительно необходимо.

Как было указано выше, Закон закрепил только право наследования учетной записи, но не регламентировал права и обязанности наследника, опекуна, доверителя, возникающие в связи с переходом к 
ним информации, которой они не могли распоряжаться при жизни умершего. Возникают вопросы: могут ли лица, получившие в собственность логин и пароль от личного кабинета, полностью распоряжаться таким объектом, в том числе продать его третьим лицам? От чьего лица будут совершаться такие действия? Как идентифицировать собственника страницы, если первоначальный пользователь указал о себе недостоверную информацию? Что будет являться доказательством, при невозможности достоверно идентифицировать личность, которой принадлежит учетная запись?

В Российской Федерации в статье 1112 Гражданского кодекса РФ (далее - ГК РФ) закреплены объекты, которые могут передаваться по наследству. К ним относятся: вещи, иное имущество, имущественные права и обязанности. Согласно этой же статьи, не могут передаваться по наследству права и обязанности неразрывно связанные с личностью [5].

В соответствии с указанием в законе на невозможность наследования прав и обязанностей, связанных непосредственно с личностью наследодателя, необходимо сделать вывод, что включение в наследство учетной записи, личного кабинета, логина и пароля будет являться нарушением в том числе ч. 2 статьи 23 Конституции Российской Федерации, которая закрепляет тайну переписки, телефонных переговоров, почтовых, телеграфных и иных сообщений. Ограничение этого права допускается только на основании судебного решения [6], так как с передачей права полного распоряжения всей информацией, размещенной на странице пользователя, правополучатель приобретает информацию, закрепленную в сообщениях, что прямо противоречит действующему законодательству.

Однако все же представляется, что в России не существует запрета на наследование учетных записей социальных сетей, но и в законе такое право не закрепляется. Одной из причин невозможности включения такого объекта в наследственную массу является то, что он не обладает признаками ни одного объекта гражданских прав, закрепленных в статье 128 ГК РФ [7].

Однако операторы (социальные сети), понимая значимость размещения информации умершего человека на просторах сети Интернет для его близких людей, в Правилах использования предусмотрели возможные выходы из рассматриваемых ситуаций. Так, в России Twitter [8], Google+ [9] предоставляют право близким родственникам и правопреемникам умершего или человека, признанного недееспособным, обратиться с просьбой об удалении аккаунта. Для этого необходимо заполнить заявление и предоставить документ, подтверждающие родство заявителя и умершего, свидетельство о смерти, документ, на основании которого действует лицо (доверенность, свидетельство о праве на наследство, решение суда и другие). Facebook [10] и Instagram [11] 
помимо возможности удаления предоставляет возможность установления для аккаунта памятного статуса, который не дает вносить какиелибо изменения в профиль, отправлять личные сообщения.

Указанные выше социальные сети, закрепляя положение о том, что наследник, получивший доступ к аккаунту, не может полностью распоряжаться им, тем самым защищают права автора на результаты интеллектуальной деятельности. Так, в статье 1112 ГК упоминается о невозможности перехода по наследству прав и обязанностей неразрывно связанных с личностью наследодателя, однако в статьях 1241, 1283, 1293, 1318 ГК, допускается переход исключительного права в порядке универсального правопреемства на результат интеллектуальной деятельности и на средство индивидуализации. В соответствии с законодательством, наследник получает неимущественные права в отношении произведений науки, литературы, искусства (например, право на обнародование - п. 3 ст. 1268 ГК, охрану (защиту) прав авторства, имени автора и неприкосновенности произведения - П. 2 ст. 1267) [12]. Однако упоминание об этом в законе по отношению к социальным сетям не имеет смысла, так как передать в порядке универсального правопреемства логин и пароль по российскому законодательству невозможно.

Следует сказать, что в указанном вопросе дело все же сдвинулось с мертвой точки. Так, с 1 сентября 2018 г. завещатель будет вправе возложить на наследника такие обязанности неимущественного характера, как действия по погребению наследодателя в соответствии с его волей [13].

Следует сказать о том, что Google+ и Gmail шагнули дальше своих конкурентов, т.к. они предоставляют пользователю право «завещать» свой аккаунт [14], а именно: в случае если пользователь не активен в течение определенного времени, то ресурс, где создана учетная запись, передает данные о ней третьему лицу, которое указал пользователь.

В результате изученного нами теоретического и практического материала, относящегося к предмету исследования, мы приходим к выводу, что Facebook и Google+ ближе всех находятся к истине. Закрепление в законодательстве наследования интеллектуальных прав в виде учетной записи в социальных сетях несомненно внесло бы ясность в непростые правовые отношения "виртуального" мира, что поспособствовало бы совершенствованию законодательства, и в наибольшей мере соответствовало бы существующим реалиям.

References:

[1] Substitute Senate Bill No. 262. Public Act No. 05-136 «An act concerning access to decedents' electronic mail accounts», Approved June 24, 2005.

[2] «Что случается с аккаунтами в интернете после смерти владельца» [Электронный ресурc] URL:http://www.cossa.ru/152/98997/ (дата обращения 10.11.2017).

[3] An Act To Amend Title 12 of The Delaware Code Relating To Fiduciary Access To Digital Assets And Digital Accounts [Электронный pecypc] URL: 
https://legiscan.com/DE/text/HB345/id/1023563 (дата обращения:10.11.2017).

[4] An Act To Amend Title 12 of The Delaware Code Relating To Fiduciary Access To Digital Assets And Digital Accounts [Электронный pecypc] URL: https://legiscan.com/DE/text/HB345/id/1023563 (дата обращения:10.11.2017).

[5] Гражданский кодекс Российской Федерации (часть третья) от 26 ноября 2001 № 146-Ф3 (ред. от 28.03.2017) // СЗ РФ. 2001. №49. Ст.4552; 2017. № 14. Ст.1998.

[6] Конституция Российской Федерации от 12 декабря 1993 г. ч. 2. Ст. 23 // С3 РФ. 04.08.2014, № 31, ст. 4398.

[7] Гражданский кодекс Российской Федерации (часть первая) от 30 ноября 1994 N 51-ФЗ (ред. от 29.07.2017) // СЗ РФ. 1994, № 32, ст. 3301.

[8] Обращение в Твиттер в связи со смертью пользователя или в связи с медиафайлами, относящимися к умершему члену семьи [Электронный реcypc] URL:https://support.twitter.com/articles/20174913?lang=ru (дата обращения 10.11.2017).

[9] Справка (Аккаунт Google). Запрос на доступ к аккаунту умершего пользователя [Электронный ресурс] URL:https://support.google.com/accounts/troubleshooter/6357590?visit_id= 1-636458926596465842-2118874476\&rd=1(дата обращения 10.11.2017).

[10] Я хранитель. Как управлять профилем на Facebook, для которого установлен памятный статус? [Электронный ресурс] URL:https://www.facebook.com/help/828408313868251?helpref=about_cont ent (дата обращения 10.11.2017).

[11] Как сообщить об аккаунте умершего человека на Instagram? [Элеткронный pecypc]

URL: https://help.instagram.com/264154560391256?helpref=search\&sr=5\&query $=\% \mathrm{D} 1 \% 83 \% \mathrm{D} 0 \% \mathrm{~B} 4 \% \mathrm{D} 0 \% \mathrm{~B} 0 \% \mathrm{D} 0 \% \mathrm{BB} \% \mathrm{D} 0 \% \mathrm{~B} 5 \% \mathrm{D} 0 \% \mathrm{BD} \% \mathrm{D} 0 \% \mathrm{~B} 8 \% \mathrm{D} 0 \% \mathrm{~B}$ 5 (дата обращения 10.11.2017).

[12] Гаврилов В.Н. Наследование имущества предпринимателей // Предпринимательское право. Издательская группа «Юрист», 2010. № 3. С. 35-39.

[13] Федеральный закон от 29 июля 2017 № 259-ФЗ // СЗ РФ. 2017. № 31 (Часть I). Ст. 4808.

[14] Политика конфиденциальности Google [Электронный ресурс] URL:https://www.google.com/policies/privacy/?hl=ru (дата обращения 10.11.2017). 